\title{
Development of High Sensitivity Eight-Element Multiplexed Fiber Laser Acoustic Pressure Hydrophone Array and Interrogation System
}

\author{
Ming $\mathrm{LI}^{1,2}$, Zhihui SUN ${ }^{2}$, Xiaolei ZHANG ${ }^{2}$, Shujuan $\mathrm{LI}^{2}$, Zhiqiang SONG ${ }^{2}$, \\ Meng WANG ${ }^{2}$, Jian $\mathrm{GUO}^{2}$, Jiasheng $\mathrm{NI}^{2}$, Chang $\mathrm{WANG}^{2^{*}}$, \\ Gangding $\mathrm{PENG}^{3}$, and Xiangang $\mathrm{XU}^{1}$ \\ ${ }^{1}$ State Key Laboratory of Crystal Materials, Shandong University, Jinan, 250100, China \\ ${ }^{2}$ Jinan Research Center, Laser Institute of Shandong Academy of Sciences, Jinan, 250014, China \\ ${ }^{3}$ School of Electronic Engineering and Telecommunication, University of New South Wales, Sydney, 2052, Austrilia \\ *Corresponding author: Chang WANGＥ-mail: ch_wangs@163.com
}

\begin{abstract}
Fiber laser hydrophones have got widespread concerns due to the unique advantages and broad application prospects. In this paper, the research results of the eight-element multiplexed fiber laser acoustic pressure array and the interrogation system are introduced, containing low-noise distributed feedback fiber laser (DFB-FL) fabrication, sensitivity enhancement packaging, and interferometric signal demodulation. The frequency response range of the system is $10 \mathrm{~Hz}-10 \mathrm{kHz}$, the laser frequency acoustic pressure sensitivity reaches $115 \mathrm{~dB} \mathrm{re} \mathrm{Hz} / \mathrm{Pa}$, and the equivalent noise acoustic pressure is less than $60 \mu \mathrm{Pa} / \mathrm{Hz}^{1 / 2}$. The dynamic range of the system is greater than $120 \mathrm{~dB}$.
\end{abstract}

Keywords: Fiber laser hydrophone; DFB-FL; packaging sensitization; eight-element multiplex; interferometric demodulation

Citation: Ming LI, Zhihui SUN, Xiaolei ZHANG, Shujuan LI, Zhiqiang SONG, Meng WANG, et al., "Development of High Sensitivity Eight-Element Multiplexed Fiber Laser Acoustic Pressure Hydrophone Array and Interrogation System," Photonic Sensors, 2017, 7(3): 253-260.

\section{Introduction}

Optical fiber hydrophones have been used in the military, marine monitoring, resource exploration, and other aspects of the application because of strong advantages after several decades of continuous research and development. The United States of America and other developed countries have begun to equip and deploy fiber hydrophones. In China, the research of fiber hydrophones is limited by the optical fiber production technology and the development of the grating writing technology, which started late but goes fast. National University of Defense Technology, Institute of Acoustics, Chinese Academy of Sciences, and other units have done a lot of research on the optical fiber hydrophone and achieved fruitful results. Recently, the research on the fiber laser hydrophones gets a wider range of concerns, dues to unique advantages of small size, high sensitivity, dynamic range, and so on.

In 2012, Y. Leguillon discussed the factors that affect the accuracy of the sensor and the factors that affect the number of sensor arrays. The sensor array,

Received: 19 April 2017 / Revised: 5 June 2017

(C) The Author(s) 2017. This article is published with open access at Springerlink.com

DOI: $10.1007 / \mathrm{s} 13320-017-0426-0$

Article type: Regular 
consisting of 12 distributed feedback (DFB) fiber lasers with a pumping source of $200 \mathrm{~mW}$ of $1480 \mathrm{~nm}$, had very low intensity noise and frequency noise [1]. In 2013, Scott Foster developed a fiber laser hydrophone device, which was deployed to the south coast of Australia $33 \mathrm{~m}$ deep seabed for a field test. It was the first time that a fiber laser hydrophone tested the sea state zero (SS0) [2]. In 2014, F. X. Launay introduced a two-dimensional array of 12 fiber laser hydrophones with a pressure sensitivity of $103.5 \mathrm{~dB}(\mathrm{re} \mathrm{Hz} / \mathrm{Pa})$ at $1 \mathrm{kHz}$ [3]. In China, the 23rd Institute of China Electronics Technology Group, Navy Engineering University, and National University of Defense Technology have done a lot of research on the systematic fiber laser hydrophone technology [4-6], and this work is mainly concentrated on the hydrophone basic technology and reuse tests. These results have laid an important foundation for further research on fiber laser hydrophone systems, but there is still a lot of work to do to achieve a comprehensive breakthrough in application technology. In 2008, W. T. Zhang reported an experiment of distributed feedback fiber laser (DFB-FL) hydrophone packaging [7].This package structure was relatively flat in frequency response under $1 \mathrm{kHz}$ frequency range, which showed the fiber laser hydrophone application has taken a key first step. In 2012, W. T. Zhang et al. used hydrophone array of eight fiber lasers, to place an underwater sounder, which was $8 \mathrm{~m}$ underwater, and $5 \mathrm{~km}$ away for the field test in Qiandao Lake of Zhejiang Province. From the test, the authors founded that the response consistency of the hydrophone unit was good, and the test value conformed to the theoretical value [8]. In 2014, H. C. $\mathrm{Gu}$ who is from Institute of Acoustics, Chinese Academy of Sciences, introduced a linear dragging array containing four fiber laser hydrophones. The sensitivity of a single hydrophone was about $-135 \mathrm{~dB}$. In the range of $20 \mathrm{~Hz}$ to $1 \mathrm{kHz}$, the amplitude fluctuation was less than $\pm 1.5 \mathrm{~dB}$ [9].

This paper systematically introduces the research results of the Laser Research Institute of Shandong Institute of Science and Technology in the high sensitivity of the eight-element multiplexed array fiber laser acoustic pressure hydrophone system. The laser frequency acoustic pressure sensitivity of the fiber laser hydrophone system is $115 \mathrm{~dB} \mathrm{re} \mathrm{Hz} / \mathrm{Pa}$ in the frequency range of $10 \mathrm{~Hz}-10 \mathrm{kHz}$, the equivalent noise acoustic pressure is less than $60 \mu \mathrm{Pa} / \mathrm{Hz}^{1 / 2}$, and the dynamic range of the system is greater than $120 \mathrm{~dB}$.

\section{Fabrication of distributed feedback fiber laser}

Fiber laser is the key sensor of the fiber laser hydrophone. Firstly, the laser output power determines the signal to noise ratio of the sensor signal. Secondly, the laser mode competition, including vertical mode competition and polarization mode competition, will affect the demodulation stability of the fiber laser hydrophone system. Thirdly, the intensity of the laser noise and frequency noise will eventually be converted into hydrophone system's phase noise, which affects the system's minimum detectable signal and dynamic range. We have a grating fabrication and testing system based on argon ion laser. As shown in Fig.1, a phase-shifted fiber grating is fabricated by the dynamic phase mask method and scanning exposure method. The phase mask's position is controlled by the nano-precision piezoelectric actuator, which can be put in phase shift accurately in the grating at any position and produce a reliable asymmetric distributed feedback fiber laser (DFB-FL).

The DFB-FL uses a single grating written on the active fiber as the gain medium and the resonant cavity. The laser's structure is simple so that it can avoid laser mode hopping. The early research shows that the $\lambda / 4$ phase shift gratings have a minimum pumping threshold and a stable single longitudinal mode operating performance when the grating factor $(k l)$ is at 10 or so $[10,11]$. When the erbium-doped phase-shifted fiber Bragg grating is fabricated, the 
length of erbium-doped fiber is $45 \mathrm{~mm}$, on which the phase-shifted grating with the length of $42 \mathrm{~mm}$ is written, the grating factor is between 10 and 12 , and the $\pi$ phase shift point is in the scale position of $4: 6$ [12]. The output wavelengths of the asymmetric DFB-FL are $1528 \mathrm{~nm}-1552 \mathrm{~nm}$, the output optical power ratio is more than $100: 1$, the line width is less than $15 \mathrm{kHz}$, and the relative intensity noise is less than $-100 \mathrm{~dB} / \mathrm{Hz}$ (at $0-50 \mathrm{kHz}$ ). The DFB-FL can meet the requirements of the laser system for laser power, narrow line-width, and low noise. The power balance of eight asymmetric DFB-FLs multiplexing is less than $4 \mathrm{dBm}$.

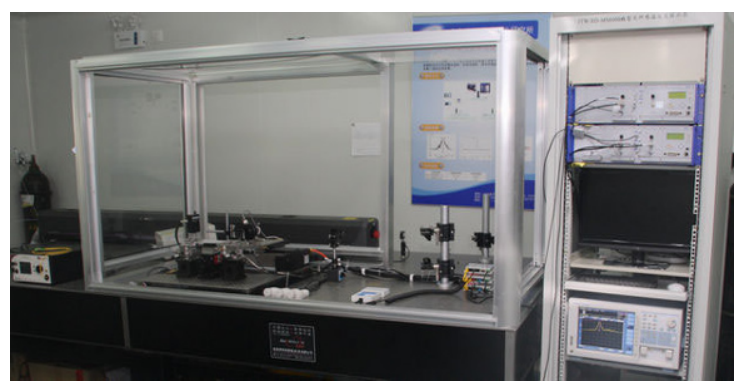

Fig. 1 Grating fabrication system of argon ion laser.

\section{Fiber laser hydrophone sensitization package}

For bare DFB-FL that has not been encapsulated, the acoustic pressure causes a small laser wavelength change (approximately $3.6 \mathrm{pm} / \mathrm{MPa}$ ). To achieve the required acoustic pressure sensitivity requirements $(>1 \mathrm{~nm} / \mathrm{MPa})$ for practical applications, DFB-FL needs sensitization package.

DFB-FL is a laser that has been inserted a $\pi$-phase shift to form a distributed feedback structure when fabricating a grating in an erbium-doped fiber. The central wavelength $\lambda_{B}$ of the laser is determined by the Bragg equation of the fiber grating as follows:

$$
\lambda_{B}=2 n_{\text {eff }} \Lambda
$$

where $n_{\text {eff }}$ is the effective refractive index of the fiber core, and $\Lambda$ is the grating period.

The influence of the ambient environment (temperature and pressure) can cause the grating period $\Lambda$ and the effective refractive index $n_{\text {eff }}$ of the DFB-FL to change, resulting in a change in the laser central wavelength $\lambda_{B}$ as follows:

$$
\Delta \lambda_{B}=2 n_{\text {eff }} \Delta \Lambda+2 \Delta n_{\text {eff }} \Lambda .
$$

The fiber laser hydrophone detects the acoustic wave signal emitted or reflected by the underwater target. The change in the sound wave in the underwater sound field leads to the change in the water pressure $P$. The sensitivity of the fiber laser hydrophone can be defined as follows:

$$
K_{p}=\frac{\Delta \lambda_{B}}{\lambda_{B} P}=\left[\frac{n_{\text {eff }}^{2}}{2}\left(P_{11}+P_{12}\right)-1\right] \frac{1-2 v}{E}
$$

where $E$ is the Young's modulus and $v$ is the Poisson's ratio of the hydrophone.

It can be seen that if the Young's modulus $E$ and Poisson's ratio of the hydrophone $v$ can be reduced by effective encapsulation, the acoustic pressure sensitivity of the hydrophone can be effectively improved [13]. By analyzing different materials, we used Divinycell $\mathrm{H}$ high performance polyurethane as the sandwich material for hydrophone packaging. The Young's modulus is about $320 \mathrm{MPa}$. It has excellent adhesion strength, superior chemical resistance, low water absorption, and excellent thermal insulation performance.

We made different structures of fiber laser hydrophone using the polyurethane material for encapsulation contrast. A water acoustic frequency response test system was set up as shown in Fig. 2 to carry out the frequency response sensitivity test of different package fiber laser hydrophones. A standard piezoelectric ceramic hydrophone RHSA-20 provided by 715th Research Institute of China Shipbuilding Industry Corporation was used to calibrate the measured sound field. Place the standard piezoelectric hydrophone RHSA-20 in the calibration field of the standing wave tube in parallel. The fiber laser hydrophone was pumped by 1480-nm semiconductor laser. Use the Michelson interferometer of $2.4 \mathrm{~m}$ arm length difference provided by the Optiphase Company for converting laser wavelength signal to phase signal. Then enter 
the phase signal into the OPD4000 signal demodulator for the signal demodulation provided by the Optiphase Company. The laser phase acoustic pressure sensitivity of the fiber laser hydrophone is defined as follows:

$$
\begin{gathered}
M_{p}=20 \lg \left(M_{\phi} / M_{r}\right) \\
M_{\phi}=\Delta \phi / P
\end{gathered}
$$

where $M_{r}=1 \mathrm{rad} / \mu \mathrm{Pa}$.

The laser frequency acoustic pressure sensitivity of the fiber laser hydrophone is defined as follows:

$$
\begin{gathered}
M_{F}=20 \lg \left(M_{f} / M_{r}\right) \\
M_{f}=\Delta v / P
\end{gathered}
$$

where $M_{r}=1 \mathrm{~Hz} / \mathrm{Pa}$.

Through the test, we found that the cylindrical package structure's sensitivity frequency response curve was the most flat, shown in Fig. 3, whose outer diameter was $8 \mathrm{~mm}$ and wall thickness was $2 \mathrm{~mm}$.

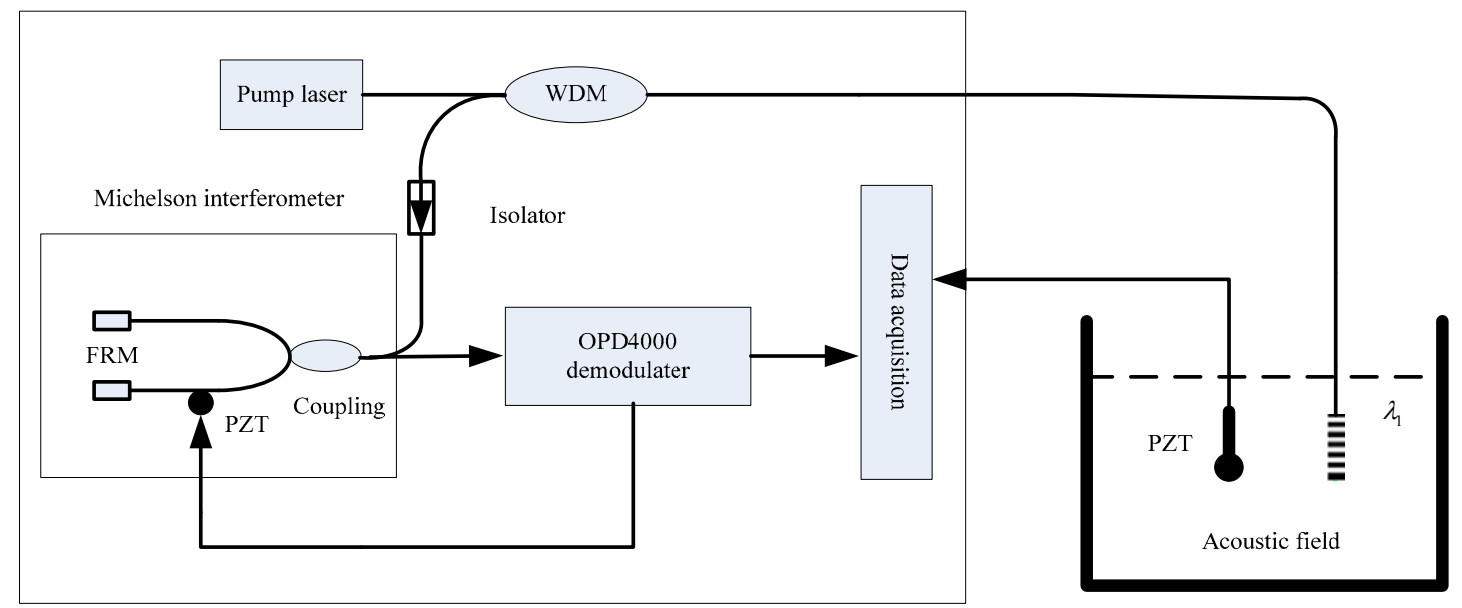

Fig. 2 Fiber laser hydrophone's sensitivity test system.
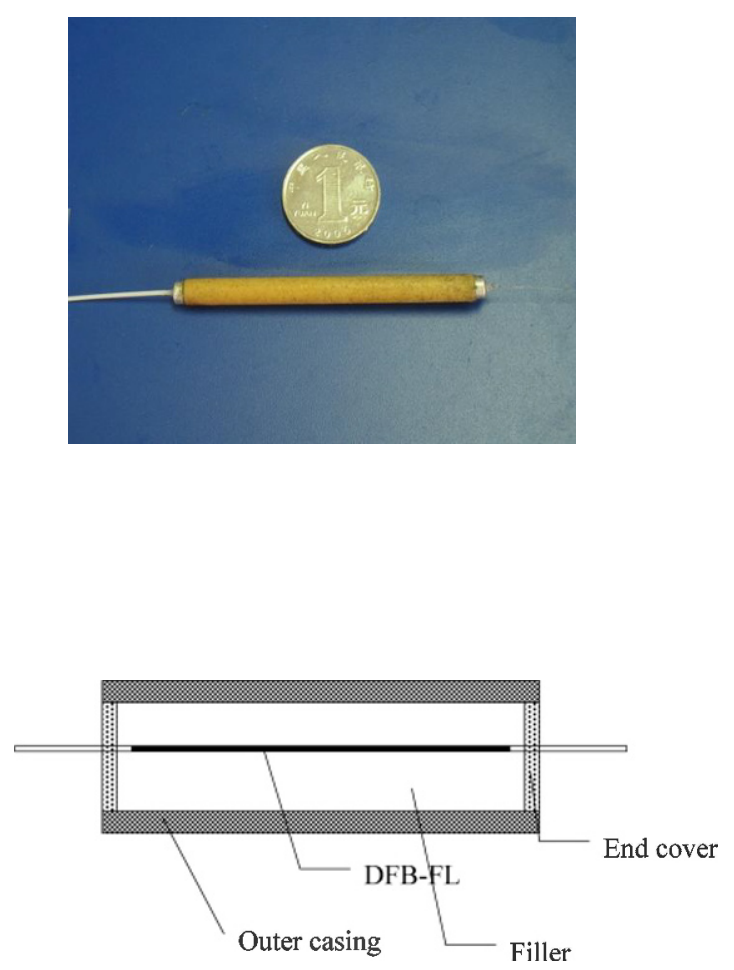
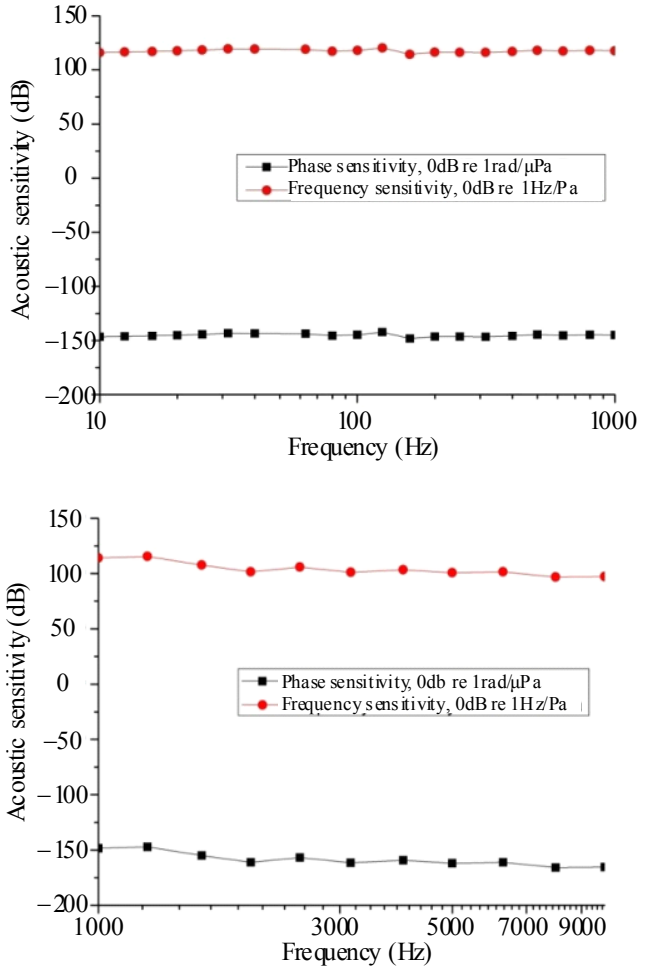

Fig. 3 Fiber laser hydrophone of cylindrical capsulation structure and its sensitivity frequency response curve. 


\section{Design of the signal interference demodulation system}

The laser generated by the DFB-FL produces the interference fringe after the fiber interferometer, and the intensity of the interference fringe is defined as follows:

$$
I=I_{1}+I_{2}+2 \sqrt{I_{1} I_{2}} \cos (\Delta \phi)
$$

where $I_{1}$ and $I_{2}$ are the intensities of two interference light beams, and $\Delta \phi$ is the phase difference of two interference light beams.

The wavelength variation $\Delta \lambda_{B}$ of the DFB-FL is transformed into phase change $\Delta \phi$ by the fiber interferometer with the arm length difference $n L$ :

$$
\Delta \phi=\frac{2 \pi n L}{\lambda_{B}^{2}} \Delta \lambda_{B} .
$$

Through the photoelectric detector for photoelectric conversion and signal demodulation, the phase change value can be got. The accurate acquisition of the hydrophone's optical phase shift is the key to the success of phase shift sensitivity detection. In this paper, the phase generated carrier (PGC) demodulation technique is used to measure the change in optical phase shift after the fiber laser hydrophone is modulated by the acoustic pressure signal. The PGC technology has the characteristics of low noise, ease to implement multiplexing, and large dynamic demodulation range [14]. We developed two methods of PGC demodulation, differential cross multiplication (DCM), and arc tangent algorithm (Arctan). The flow chart of the PGC demodulation technology is shown in Fig. 4. We made program development and optimization by LabView software and completed the demodulation algorithm performance test and calibration. The demodulation frequency range was $10 \mathrm{~Hz}-10 \mathrm{kHz}$. Its wavelength demodulation resolution rate was less than $10^{-6} \mathrm{pm} / \mathrm{Hz}^{1 / 2}$ (between $10 \mathrm{~Hz}$ and $10 \mathrm{kHz}$ ), and the linearity was larger than 0.99 . Parameters comparison of two methods is shown in Table 1. The linearity of the arc tangent algorithm is better. The total harmonic distortion (THD) of the differential cross multiplication is less. The signal to noise and distortion (SINAD) and wavelength demodulation resolution are almost the same.

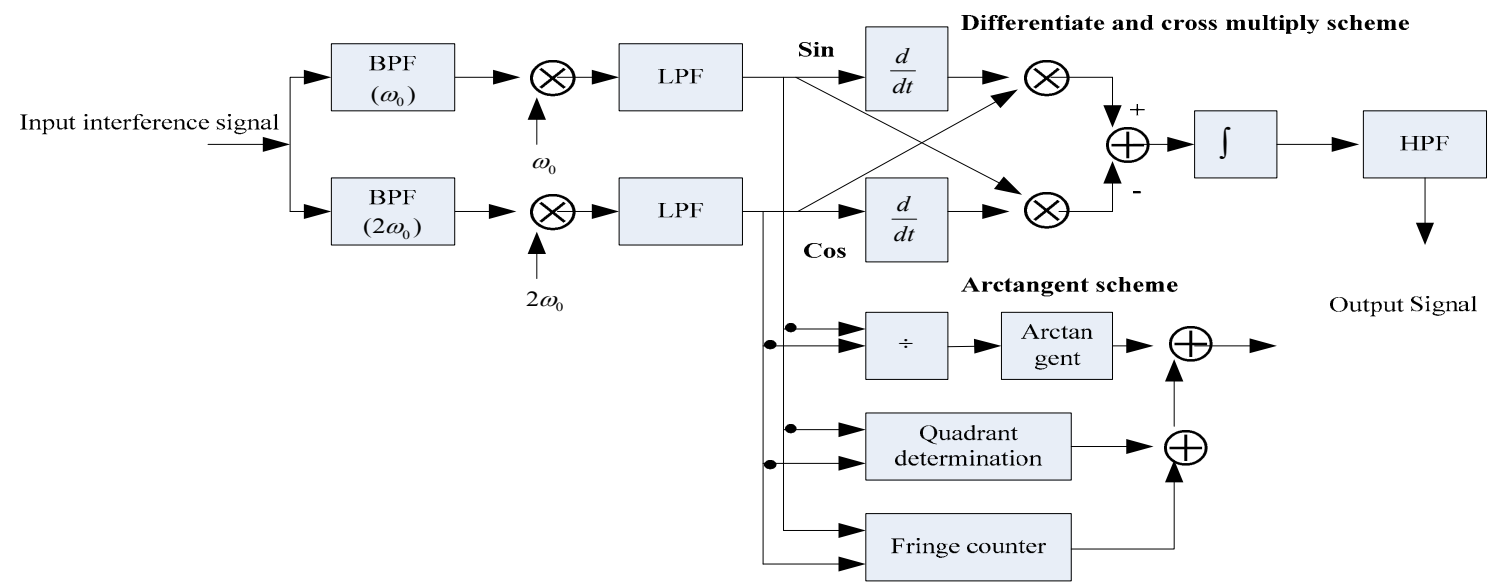

Fig. 4 Flow chart of the PGC demodulation technology.

Table 1 Parameters comparison of two demodulation methods.

\begin{tabular}{ccc}
\hline Parameters & PGC-DCM & PGC-Arctan \\
\hline Linearity & $99.40 \%$ & $99.97 \%$ \\
SINAD & $23.32 \mathrm{~dB}$ & $23.21 \mathrm{~dB}$ \\
THD & $\begin{array}{c}1.35 \% \\
\begin{array}{c}\text { Wavelength } \\
\text { resolution }\end{array}\end{array} \begin{array}{c}3.44 \% \\
\text { (at 1 kHz) }\end{array}$ & $\begin{array}{c}<10^{-6} \mathrm{pm} / \mathrm{Hz}^{0.5} \\
\text { (at 1 kHz) }\end{array}$ \\
\hline
\end{tabular}

\section{Design of eight-element multiplexed fiber laser acoustic pressure hydrophone array system}

In the wet end of system, the wavelengths of the eight DFB fiber laser hydrophones were $1528.9 \mathrm{~nm}$, $1530.1 \mathrm{~nm}, 1536.6 \mathrm{~nm}, 1539 \mathrm{~nm}, 1541.3 \mathrm{~nm}$, 
$1544.6 \mathrm{~nm}, 1546.1 \mathrm{~nm}$, and $1552.5 \mathrm{~nm}$, respectively. In the dry end of the system, the length difference of Michelson interferometric arm was $30 \mathrm{~m}$. In the case of the same phase resolution, the longer the arm length is, the higher the wavelength shift demodulation resolution is. The signal acquisition card was PXI6368 provided by NI Company. The pump laser source was a $1480-\mathrm{nm}$ semiconductor laser of $300 \mathrm{~mW}$. The system diagram is shown in Fig. 5.

By the test in the relatively quiet environment, the background noise of the fiber laser hydrophone system was about $10^{-5} \mathrm{pm}$ in the frequency range of $10 \mathrm{~Hz}-1 \mathrm{kHz}$, and the noise spectral density was $2.6 \times 10^{-7} \mathrm{pm} / \mathrm{Hz}^{1 / 2}\left(32.5 \mathrm{~dB} / \mathrm{Hz}^{1 / 2}\right)$, as shown in Fig. 6. The laser frequency acoustic pressure sensitivity was about $115 \mathrm{~dB}$ re $\mathrm{Hz} / \mathrm{Pa}$ (between $10 \mathrm{~Hz}$ and $10 \mathrm{kHz}$ ), and the dynamic range was more than $120 \mathrm{~dB}$. The equivalent noise acoustic pressure was $57.8 \mu \mathrm{Pa} / \mathrm{Hz}^{1 / 2}\left(-84.7 \mathrm{~dB}\right.$ re $\left.\mathrm{Pa} / \mathrm{Hz}^{1 / 2}\right)$ at $1 \mathrm{kHz}$, because the deep sea state zero noise pressure (DSS0) at $1 \mathrm{kHz}$ was about $100 \mu \mathrm{Pa} / \mathrm{Hz}^{1 / 2}$, and the equivalent noise acoustic pressure was less than DSS0.

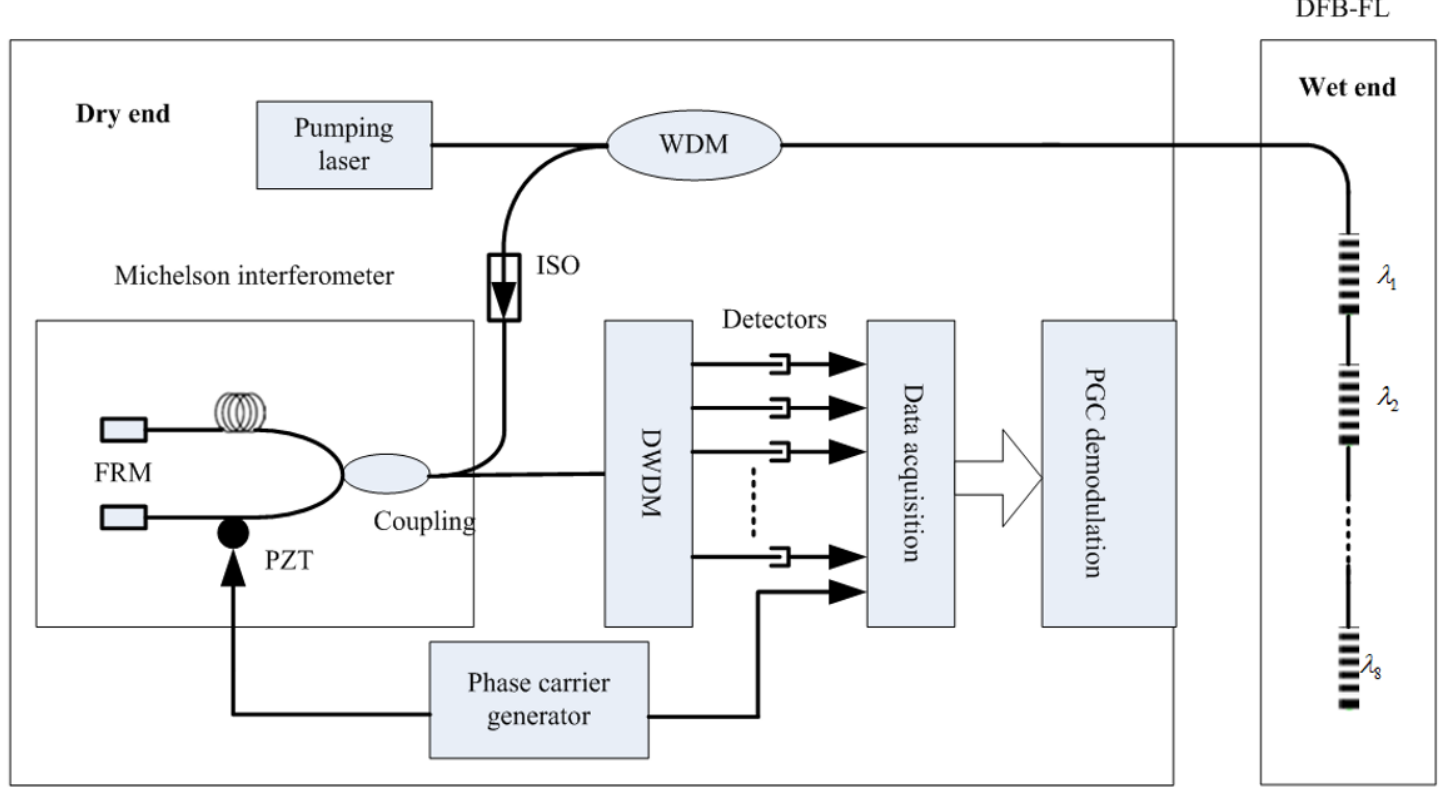

Fig. 5 Fiber laser hydrophone system schematic diagram.

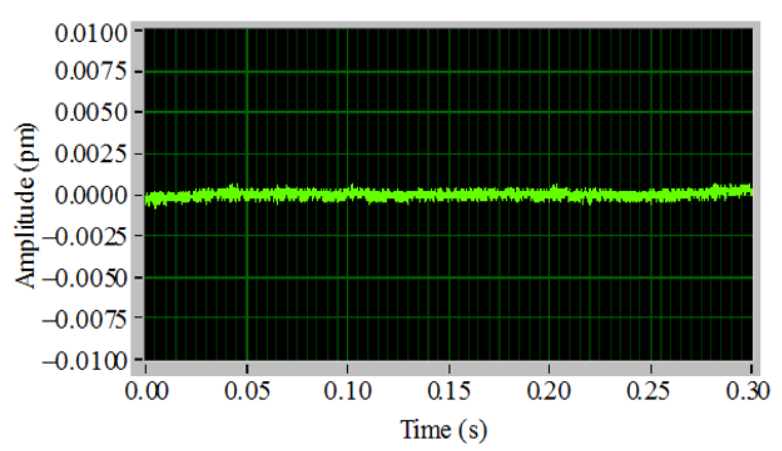

Fig. 6 Background noise of the fiber laser hydrophone system.

\section{Conclusions}

The fiber laser hydrophone has the advantages of

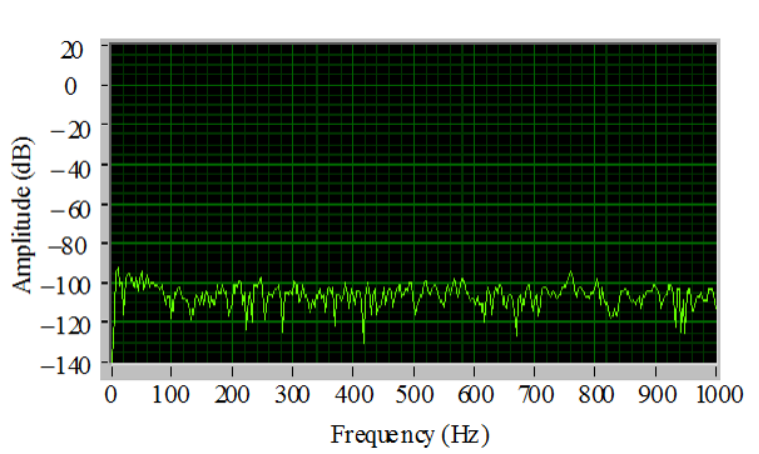

small volume, high sensitivity, large dynamic range, strong anti-electromagnetic interference, and so on. It has wide application prospects and important 
research value in military and civil fields. Abroad, the fiber laser hydrophone array has been practically applied. In this paper, we develop a wide frequency response, large dynamic range, and high sensitivity eight-element multiplexed fiber laser hydrophones array system. The low-noise distributed feedback fiber laser is used as the core component of the hydrophone, and the polyurethane is used for the sensitization package of the DFB-FL. Two different PGC technologies are developed to demodulate the signal. The frequency response range of the system is $10 \mathrm{~Hz}-10 \mathrm{kHz}$, the laser frequency acoustic pressure sensitivity reaches $115 \mathrm{~dB} \mathrm{re} \mathrm{Hz} / \mathrm{Pa}$, the dynamic range is more than $120 \mathrm{~dB}$, and the equivalent noise acoustic pressure is less than $60 \mu \mathrm{Pa} / \mathrm{Hz}^{1 / 2}$, which is lower than DSS0. The work promotes the domestic development of more than eight-element multiplexed fiber laser hydrophones array system practical process.

\section{Acknowledgment}

This work was financially supported by the National Natural Science Foundation of China (No. 60317101), Key Research and Development Plan of Shandong Province (No. 2015GSF11500), and Natural Science Foundation of Shandong Province (No. ZR2013FL029).

Open Access This article is distributed under the terms of the Creative Commons Attribution 4.0 International License (http://creativecommons.org/ licenses/by/4.0/), which permits unrestricted use, distribution, and reproduction in any medium, provided you give appropriate credit to the original author(s) and the source, provide a link to the Creative Commons license, and indicate if changes were made.

\section{References}

[1] Y. L'eguillon, K. H. Tow, P. Besnard, A. Mugnier, D. Pureur, and M. Doisy, "First demonstration of a 12 DFB fiber laser array on a $100 \mathrm{GHz}$ ITU grid for underwater acoustic sensing application," in Proceeding of SPIE Conference on Optical
Sensing and Detection II, Brussels, Belgium, 2012, pp. 17.

[2] S. Foster, A. Tikhomirov, J. Harrison, and J. V. Velzen, "Field demonstration of an 8-element fibre laser hydrophone array," in Proceeding of $23 \mathrm{rd}$ International Conference on Optical Fibre Sensors, Santander, Spain, 2014, pp. 91570H-1 $-91570 \mathrm{H}-4$.

[3] F. X. Launay, R. Bouffaron, R. Lardat, G. Roux, M. Doisy, and C. Bergogne, "Acoustic antenna based on fiber laser hydrophones," in Proceeding of $23 \mathrm{rd}$ International Conference on Optical Fibre Sensors, Santander, Spain, 2014, pp. 91570Y-1 $-91570 \mathrm{Y}-4$.

[4] Q. Zhu, X. B. Chen, J. P. Chen, and G. D. Peng, "DFB fiber laser fabrication by moving phase mask," Optical Fiber \& Electric Cable \& Their Applications, 2006, 1(1): 17-20.

[5] B. Tan and J. B. Huang, "Design about a novel encapsulation structure of DFB fiber laser hydrophones," in Proceeding of International Symposium on Photonics and Optoelectronics, Suzhou, China, 2014, pp. 92330X-1-92330X-7.

[6] L. N. Ma, "Fiber laser hydrophone," Ph.D. dissertation, National University of Defense Technology, Changsha, 2010.

[7] W. T. Zhang, Y. L. Liu, F. Li, and H. Xiao, "Fiber laser hydrophone based on double diaphragms: theory and experiment," Journal of Lightwave Technology, 2008, 26(10): 1349-1352.

[8] W. T. Zhang, F. Li, and Y. L. Liu, "Field test of an eight-element fiber laser hydrophone array," in Proceeding of 22nd International Conference on Optical Fiber Sensors, Beijing, China, 2012, pp. 8421AX-1-8421AX-4.

[9] H. C. Gu, J. B. Huang, H. B. Yu, R. Z. Li, B. Tang, and J. Wu, "A 4-element fiber laser hydrophone towed linear array," in Proceeding of International Symposium on Optoelectronic Technology and Application (IPTA)-Laser and Optical Measurement Technology and Fiber Optic Sensors, Beijing, China, 2014, pp. 92972Y-1 -92972 Y -6.

[10] S. W. Lovseth and E. Ronnekleiv, "Fundamental and higher order mode thresholds of DFB fiber lasers," Journal of Lightwave Technology, 2002, 20(3): 494-501.

[11] D. Sacastru, S. Miclos, and I. Lancranjan, "Theoptical analysis of the output noise of a FDB fiber laser sensor," International Journal of Mathematics \& Computers in Simulation, 2010, 4(4): 116-123. 
[12] Z. Q. Song, H. F. Qi, C. Wang, Y. Shang, and W. Chang, "Narrow line-width fiber laser and application in sensing," Acta Optica Sinica, 2015, 35(s2): s214005.

[13] H. Xu, C. Wang, G. D. Peng, X. L. Zhang, Y. Y. Ying, Z. H. Sun, et al., "A distributed feedback fiber laser hydrophone with high sensitivity and flat frenquency response," Shandong Science, 2013, 26(4): 46-50.

[14] Y. Chen, J. Zhang, M. Zhang, and L. W. Wang, "Calibration of phase-shifted sensitivity of optical fiber hydrophone in the frequency range $20 \mathrm{~Hz}$ to 10 kHz," Acta Optica Sinica, 2011, 40(11): 1686-1691. 